\title{
PE teaching method based on Analytic Hierarchy Process
}

\author{
Taibin Huang \\ Department of physical education, xin yu University, Xin yu, 338004, China
}

Keywords: Hierarchical Teaching Method; Physical Teaching; Assessment; Analysis

\begin{abstract}
Application of hierarchical physical teaching method to physical teaching in university is researched in this thesis. Firstly, application meaning of hierarchical teaching method in physical teaching of university is analyzed in three aspects, and then several suggestions are proposed aiming at application of hierarchical teaching method to physical teaching in university on this basis, namely: three points including fully understanding students, emphasizing rationality of hierarchical division for students and emphasizing formulation of hierarchical assessment standard, in wish of enlightening and helping physical teaching of university.
\end{abstract}

\section{Application Meaning of Hierarchical Teaching Method in Physical Teaching of University}

Application of hierarchical teaching method to physical teaching in university has positive meaning in many aspects:

Firstly, obvious individual differences exist for different aspects of students such as athletic ability, current physical basis, hobbies and interests, advantages and strong points, etc in the process of physical teaching in university. If physical course teachers in university ignore these objective individual differences among students and adopt uniform, single and sweeping approaches to organize and develop teaching activities, then physical learning demands of each student can hardly be fully satisfied, and problems that partial students "are on short commons" while other students "are unable to stand fatigue" can easily occur. Hierarchical teaching method solves this problem effectively. Hierarchical teaching method requires course teachers to conduct scientific hierarchy for students on the basis of fully understanding and mastering actual situations of them, and formulate different teaching aims, teaching plans, teaching requirements for students of different hierarchies, thus each student can obtain something in physical teaching activities and quality and level of physical teaching method in university are greatly improved.

Secondly, physical quality level and physical exercise ability of students with worse physical basis can be improved in a greater scope and physical learning interest as well as physical learning initiative of students with better physical basis can be fully motivated at the same time through applying hierarchical teaching method to physical teaching activity in university. Classified guiding for different students is realized effectively through hierarchical method, thus "teaching" and "learning" in physical teaching activity of university are more targeted and effectiveness of physical teaching in university is improved effectively.

Finally, application of hierarchical teaching method to physical teaching in university contributes to two-way communication of teaching information in physical teaching method as well self-confidence increase for students of different levels, thus passive learning can be changed to active learning for students and initiative of students in physical learning activities can be fully exerted. Students can fully experience athletic fun and it contributes to cultivation of good physical conception and physical awareness for students. 


\title{
Implementation Suggestion of Hierarchical Teaching Method in Physical Teaching of University
}

\author{
Course teachers shall fully understand students to implement hierarchical teaching \\ successfully
}

Whether physical course teachers have a comprehensive and objective understanding of students is a key issue to affect smooth and efficient implementation of hierarchical teaching method in physical teaching of university. Physical course teachers shall design corresponding teaching requirements, organize corresponding teaching content, select corresponding teaching method aiming at different situations and different physical learning levels of students to realize scientific application of hierarchical teaching method in the process of developing physical teaching activities, thus students of different levels can all obtain development to the greatest degree and fully feel fun of physical learning and physical exercise. So the most prominent feature of hierarchical physical teaching process is teaching students according to their aptitudes and individual differences. Physical course teachers shall have a comprehensive and objective understanding of students, master actual situations such as current physical quality basis, physical exercise level, physical learning ability, psychological quality condition, physical hobbies and interests, ages and personality, etc practically and have a scientific mastering and assessment for comprehensive ability of students to lay a good basis for the application of hierarchical teaching method to physical teaching method of university before formulating corresponding teaching goal and teaching requirements and determining corresponding teaching content and teaching method so as to achieve this point.

Hierarchical reasonable division of student shall be noticed to implement hierarchical teaching method successfully

Hierarchical division of students is a process to conduct division according to many factors of students themselves affecting development of physical teaching activity and progressive relationship step by step rather than simple grouping for students when hierarchical teaching is applied in physical teaching of university. In this process, many factors of students themselves affecting development of physical teaching activity refer to all conditions imposing certain influence on physical teaching activity in university mentioned hereinbefore, such as physical quality basis, physical exercise level, physical learning ability, personality and hobbies, etc. These are important hierarchical basis of students in physical teaching activity in university. Whether physical course teachers can conduct reasonable hierarchical division for students according to these factors will impose a series of interlock influence on successive teaching process, and it can finally affect quality and level of physical teaching of university. Thus, physical course teachers shall conduct scientific hierarchy for students according to these actual situations.

Besides, hierarchical division of students in physical teaching activity is a process to notice learning situations and self ability changing situations for students at any time in dynamic view, and to adjust hierarchy of students continually according to actual situations of changes rather than a process of once for all or an item of changeless work after division, and hierarchical scientific nature and rationality for students can be sustained all the time only by this.

Formulation of hierarchical assessment standard shall be noticed to implement hierarchical teaching successfully

Partial physical teachers fully recognize the importance of links such as layering of teaching goals, teaching content and students, etc, but they often ignore the function of hierarchical assessment when they implement hierarchical teaching in physical teaching of university. While in reality, although work such as layering of teaching goal, teaching content and students, etc is well conducted at the time of applying hierarchical teaching method in physical teaching and hierarchical assessment is ignored, and physical assessment of uniform standard and requirements is still implemented, then initiative of students with not ideal learning situations will still be bruised inevitably in the assessment. And learning level of students on higher level cannot be fully motivated at the same time, thus it will produce adverse affect on improvement of teaching quality. 
It can be seen from this that layering of learning assessment for students is also very key, and physical course teachers shall emphasize formulation of standard of hierarchical assessment to implement hierarchical teaching successfully. Pertinent adjustment shall be conducted on content and requirement of assessment according to student level, namely increasing assessment difficulty properly for high-level students and lowering assessment difficulty for low-level students, thus objective, comprehensive, scientific assessment evaluation can be realized on learning situation of students and motivation function of teaching evaluation can be fully exerted.

\section{Application of Hierarchical Method to Physical Teaching}

\section{Determination of teaching goals of all levels}

Formulation of teaching goal is divided into overall goal, stage goal and class goal. Different teaching goals should be proposed for students of different levels, and determination of goals shall conform to practical situation of students. Combination of qualitative and quantitative indexes shall be adopted to make each student achieve goals through efforts according to features of physical teaching materials. Practice has proved that the first level is $100 \%$, and the second level is $85 \%$, and the third level is over $60 \%$ on achievement of teaching material for determination of stage goals. Content shall be added for good students, and medium students shall complete one, and weak students shall complete one of two in the aspect of content for determination of class goal. Higher requirement shall be proposed for the first level, and difficulty shall be lowered for other levels properly on requirements of completion times, distance, time and quality.

In teaching, up to par teaching is the central link of hierarchical teaching, and all teaching activities shall be developed surrounding teaching goals. Flexible, various and effective teaching methods shall be adopted for teaching in order for up to par teaching according to students of different levels. For example, principle of "low starting, running at medium speed and sprinting well" is adopted for teaching to fully motivate initiative of learning and exercise for students of different levels and improve students' ability on the original basis of different levels.

\section{Adopting teaching organization method according to hierarchical physical ability}

Students in experimental class shall be divided into three levels including good, medium and bad levels according to physical ability situation of students and measured data beforehand. I selected five items such as 50-meter running, return running of 50 meter $\times 8$, standing long jump, sit-up, softball, etc for test and layering. Performance over 380 scores is good, and performance between $270 \sim 375$ scores is medium, and performance below 265 scores is bad in total scores of the five items. This layering is not fixed, which shall be changed once a year or a semester.

Above layering and grouping are both conducted on the basis of totals scores of the five items for students and suitable for comprehensive classified boosting. Temporary grouping teaching can be conducted according to physical ability, skills, psychology and difference teaching materials, teaching content as well as actual situation of students to implement classified boosting of single items better. For example, after students exercise for several times according to original fixed order when everyone is learning goat jumping with legs apart, there may be someone who is able to complete it independently, someone who can complete it with help of the teacher and classmates, someone who fails to complete it. Then the teacher can adopt flexible grouping method for teaching and conduct grouping teaching according to completion degree, and all levels can rise and fall at any time to achieve the purpose of improving teaching profit.

\section{Teaching knowledge, technology and skills to students in hierarchy}

Enlightening and guiding. Teachers shall select attempt points and design orders of problems and exercise according to key and difficult points of teaching materials. In teaching process, teachers shall firstly observe and discuss problems initiatively to make students form cognition contradictories and thus motivate learning desire of students.

Knowledge and skills shall be learnt. Teachers shall fully exert learning initiative of students, set attempt level suitable for levels of students, and students commonly conduct the following several activities: observing demonstration of the teachers, analyzing teaching materials, reviewing certain 
skills, exercising and experiencing actions, comparing learned technical movement, finding new knowledge and skills in exercise and research, solving proposed problems to achieve the purpose of mastering new knowledge, skills and technology.

Proper exercise shall be conducted to strengthen skill forming. Teachers can allocate some quality exercise for general teaching goals to be completed; teachers can allocate some auxiliary and inductive content, prepare exercise order for students to exercise repeatedly on teaching materials of strong technology. Proper gradient shall be noticed at the time of arranging exercise content, and creative factors can be increased gradually. Sometimes certain actions can be extended and changed properly to combine it with overall learning process organically. Students of different levels shall be treated in distinction at the same time.

Teaching effect shall be fed back promptly. Teachers shall collect and assess learning effect of students at any time in the process of exercise, such as observing actions, raising questions and analyzing, assessment, etc. Exercise shall be organized in pertinence through feeding back assessment result promptly.

\section{Acknowledgements}

Humanities and social science research project of universities and colleges in Jiangxi. Project number: TY1528.

\section{References}

[1] Dalia S. Abdelhamid, Yingyue Zhang, Daniel R. Lewis, Prabhas V. Moghe, William J. Welsh, and Kathryn E. Uhrich, Tartaric Acid-based Amphiphilic Macromolecules with Ether Linkages Exhibit Enhanced Repression of Oxidized Low Density Lipoprotein Uptake, Biomaterials, 2015, 53, 32-39.

[2] Yingyue Zhang, Jennifer W. Chan, Alysha Moretti, and Kathryn E. Uhrich, Designing Polymers with Sugar-based Advantages for Bioactive Delivery Applications, Journal of Controlled Release, $2015,219,355-368$.

[3] Yingyue Zhang, Qi Li, William J. Welsh, Prabhas V. Moghe, and Kathryn E. Uhrich, Micellar and Structural Stability of Nanoscale Amphiphilic Polymers: Implications for Anti-atherosclerotic Bioactivity, Biomaterials, 2016, 84, 230-240.

[4] Jennifer W. Chan, Yingyue Zhang, and Kathryn E. Uhrich, Amphiphilic Macromolecule Self-Assembled Monolayers Suppress Smooth Muscle Cell Proliferation, Bioconjugate Chemistry, 2015, 26(7), 1359-1369.

[5] Yingyue Zhang, Evan Mintzer, and Kathryn E. Uhrich, Synthesis and Characterization of PEGylated Bolaamphiphiles with Enhanced Retention in Liposomes, Journal of Colloid and Interface Science, 2016, 482, 19-26. 